of bipolar groups, where they often diverge, not from the magnetic poles (i.e. the spots themselves) but from bright eruptive centres at some distance from them. Nevertheless, as I shall show later, there still exist several difficulties in the way of accepting a purely hydrodynamical explanation of the structure accompanying single and double spots, and I am therefore reserving judgment until further studies can be made.

Whatever the results of these studies may be, I have already shown that many single spots are surrounded by hydrogen whirls, about 80 per cent. of which correspond in direction with terrestrial cyclones. We may therefore formulate an empirical law defining the direction of whirl of single gyrating solar storms (Fig. 7). For the high-level whirls shown by the hydrogen flocculi, this corresponds

\section{The Exhibition of the}

DAsS ASSING through the eleven galleries, in which 738 selected oil paintings of the year are displayed, the attention of any student of Nature is due perhaps to landscapes and other out-of-door pictures in preference to portraits, genre, or still-life, and with the critical habit that clothes the orthodox scepticism of the scientific mind, his first instinct is to point out how his colleagues of the brush and palette have failed to appreciate the shapes and colours of natural objects of their common care. It is, however, permissible to reverse the order, and taking the representations as real (wherever possible), to gather what the artists have to tell us about Nature that ought to come within the thought of our philosophy. In this year's Academy there is a fine picture of crepuscular rays with layers of cloud, "The Coming and the Going" (319), by C. Conway Plumbe, quite a good subject for a meteorological lecture.

Prominent in any exhibition of paintings are the colour of the sky and its gradation from a real blue up above, almost the cerulean blue of the poets, through a paler and still paler blue or green to a filmy, hazy white, or even dull grey, along the horizon, with or perhaps without any definite cloud in the visible sky. There are generally plenty of examples in any exhibition, and this one is no exception. In "Looking on to Antibes from Cagne, France" (162), Sir H. Hughes-Stanton gives a very good example; the same artist's picture of "Cagnes, Alpes Maritime, France" (241), is also typical, and in "Blackberries" (396), Harold Harvey has the gradation even too well marked. "The River Mill" (14), by Arnesby Brown, is also good. With less definite colour, "Shadow and Shine, Lake-end, Ullswater" (268), and "Loch Morar" (140), Sir David Murray, show beautiful gradation, and "November" (274), Hughes, is good enough. If we can believe what the artists tell us, there are days and places where the nebulous whiteness covers the whole sky and the gradation is of cloudiness, from the whitening of the blue above to the leaden skies which are characteristic of the British Isles. We can find examples of that kind of nebulosity in "Grey in all sunspot cycles to the terrestrial law, counterclockwise in the northern hemisphere and clockwise in the southern hemisphere. For the underlying vortices which constitute sunspots the actual direction of whirl is not known, but we may safely infer from the resultant magnetic polarity of the spots that it is opposite in the northern and southern hemispheres and that it reverses at each sunspot minimum. In Fig. 7 the whirls represent the hydrogen flocculi and the letters $\mathrm{N}$ and $\mathrm{S}$ the magnetic polarities of the underlying spots in three successive cycles. A general law probably cannot be formulated for the hydrogen whirls above bipolar spots, but for the bipolar spots themselves the law has been given in a previous article. ${ }^{10}$

10 "Sunspots as Magnets and the Periodic Reversal of their Polarity," NATURE, Jan. 19,1924 .

\section{Royal Academy, I927.}

Morning" (35), by Arthur E. Law, and "Sand Dunes on the Kentish Coast" (36), by Oliver Hall. W. L. Wyllie has the same touch in his picture "Waterloo: The Doomed Bridge" (128) and his "A Suggestion for the New Charing Cross Bridge" (139). W. W. Russell, in "Rochester: Evening" (53), also gives us an example of pervading and graduated greyness.

Artists, indeed, clearly differentiate themselves by their appreciation of detail and of colour ; some see the blue and its gradation, and some apparently are more apt to see the greyness, or only paint a landscape when it is suffused with grey. The difference of habit is perhaps not all temperament. The photographic eye, which in these days ranges beyond the visible on either side, shows the same kind of discrimination. A photograph in the light of the extreme red is conspicuous for its clear definition, whereas the same landscape in ultraviolet light is hazy. An exhibition of paintings moves us to wonder whether different eyes are in some way sensitive beyond the visible range and whether some artists specialise in the infra-red, while others range themselves with the ultra-violet.

This carries us from the landscapes to the portraits, for in them we find an echo of the same kind of difference. Some portraits are meticulously detailed and not infrequently also ruddy, while others are suffused with a sort of mistiness and have a paler cast. The portraits by Orpen are conspicuous for their definition and their colour. In (723) Prof. J. A. Fleming forces a hard smile while floating in a sea of scarlet and yellow. Lavery, in like manner, has marked definition and bold colour ; but Solomon J. Solomon paints The Right Rev. the Lord Bishop of Worcester (44) in the more hazy part of the spectrum and with less violent definition.

Talking about culture and civilisation, philosophers have classed art, music, literature, and the mathematics as corresponding expressions of human genius and, like the rest of them, the artist expresses by his treatment not merely his subject but also himself. His true aim is not a perfect autochrome but something that through the material displays the 
divinity that shapes his ends and ours. His claim that he can paint only what he sees must be set aside. Through the pictures we can obtain a sort of line spectrum of the artist. There is a good deal of interest in carrying that idea with one through the Academy exhibition. Of course the artist is not everything; the sitter as the medium of expression counts for something. It is clear from the exhibition that men are mostly clothes, sometimes little else, and women, with here and there an exception, are jewel stands. Clerics have a strong vein of pessimism, with the exception of the Bishop of Worcester; 'dons' are complacently resigned; politics, commerce, and industry are built up round an artificial smile; and marquesses are sly-very sly. But in spite of these intrusions into the natural spectrum we have to ask ourselves what are the lines belonging to the artist. For Orpen there is a strong line of realism and humanity towards the infra-red; he even goes so far as pinning down the unavoidable humanity of Miss Penelope Lawrence, M.D. (143), though he excuses women more easily than men. So does Sir John Lavery. Outside humanity there are not many lines in Orpen's spectrum. We can find more in Jack's picture of H.M. The Queen (133), and still more in his "The Blue Drawing-Room, Buckingham Palace"(103). There is something, too, in La Thangue's "Tying Watercress" (255) and Mrs. Dod Procter's "Morning " (735). W. W. Russell's spectrum is so nearly continuous that he seems to be waiting for a reincarnation either of himself or his sitters to suggest a relation of life's enigmas.

If a crowd round a picture at the private view is any clue to its greatness, "Paolo and Francesca" (179), by F. Cadogan Cowper, seemed to be the favourite, and certainly it is an impressive scheme of colour; but still more on the side of the mystery of divinity is "The Enchanted Road" (350), by F. O. Salisbury, or "Svilata, Avati and Augali Sen, Daughters of Mr. and Mrs. Rimsod Sen" (652), by the same artist, and Clausen's "The Nut-brown Maid" (566). The mystery is not confined to portraits; it is quite impressive in "Theatre Marcellus" (75), by Sydney Lee, though the picture belongs to the red end of the artistic spectrum. But spectrum analysis of character is a perplexing study. Those who visit the Academy may take with them their own instruments. "Quai des Grands Augustins, Paris" (86), by Charles Cundall, is good for demonstration.

\section{Obituary.}

Prof. E. H. Starling, C.M.G., F.R.S. A FEW days ago news was telegraphed from on board the Ariguaing shortly before reaching Kingston. Of late years he had had indifferent health and had suffered from disabilities under which one of less heroic spirit could not have continued to work strenuously. His enthusiasm for the discovery of new truths was unimpaired, and his mind was so sympathetic and alert that it was difficult to believe he was not a sound man. Nevertheless, evidences of diminishing capacity for work without undue fatigue were obvious to his friends and a source of anxiety to them.

At the close of the winter session, during which he had been daily occupied with arduous experiments, he was very tired. The weather was cold and dull, and he longed for sunshine and warmth. He therefore decided to take a voyage to the West Indies, in full hope that this would restore his energies and enable him to continue with enjoyment the experimental work with which he was occupied. However, that was not to be, but he had the satisfaction of going down with his flag flying, as he would surely have desired.

Ernest Henry Starling was born in 1866. His father, H. H. Starling, was Clerk of the Crown at Bombay. The family of seven children had perforce to be educated in England. They therefore saw but little of their father and were brought up by their mother, an extraordinary woman, and it is to her influence by heredity and nurture that Starling owed his determination, mental alertness, and much of his charm. As the eldest boy, in the absence of a father he early acquired a sense of responsibility and capacity for managing his affairs, and was, in some respects, unusually mature for his years. He was educated at King's College School. He left at $16 \frac{1}{2}$ years of age, having matriculated at the University of London with honours, and proceeded to the study of medicine. He chose Guy's Hospital because his uncle was a Guy's man.

At this time Starling's ambition was to be a physician and live in Harley Street, and it was not until a few years later that he began to doubt the all-sufficiency of this ideal and to contemplate the possibility that he might be able to devote himself to an academic career and perhaps become a discoverer himself. As soon as he touched the study of natural science it was clear that Starling had found his métier. The causal relation of facts enthralled him. He was intensely curious, and had a naturally scientific mind. $\mathrm{He}$ was gifted with fine intellectual machinery, a good memory, industry, and possessed great powers for work, and it was soon clear to his teachers that they had a very exceptional pupil. The teachers of natural science at Guy's in those days were men of distinction, but they only called for a few hours weekly to deliver their lectures. The one who made a great impression upon Starling was Dr. Debus, of the Royal Military Academy, Woolwich, who gave part of the lectures on chemistry. He was a fine teacher, and the enthusiasm with which he expounded the elements of chemistry was infectious.

At the examination in preliminary scientific subjects at the University, Starling obtained the first place in chemistry and botany and second place in physics. He obtained so many medals and prizes as he proceeded through his medical course that an account of these academic victories at university and hospital would be wearisome. About two-thirds of the academic honours available 